of Wakefield, a lady aged seventy-six, who in early life had suffered severely from neuralgia of the stomach, which had been much aggravated by the treatment then in vogue of insufficient nutritive food and depleting remedies. This patient was seized with violent pain, affecting the nerves of the scalp, and which became so excruciating as to deprive her of sleep for many successive nights. She became delirious in consequence, and we decided to inject one quarter of a grain of morphia. This gave prompt relief and procured sleep. She was ordered turtle-soup, oysters, and an exceedingly nutritious dietary. She was well supplied with food at night also, which invariably relieved the pain. A mixture, con. taining half-drachm doses of aromatic spirit of ammonia and fifteen minims of tincture of nux vomica, seemed greatly to improve the appetite, which became prodigious and surprising. The tendency to degenerate was kept prominently in view, pure air was freely supplied in the bedroom, and every other measure taken to improve nutrition and the general health. As a local application, the chloroform liniment with tincture of opium relieved pain, and as soon as the case became chronic, the hair was cut closely and blistering fluid applied to the tender spots, which were well developed in this case; multiple abscesses formed, and were frequently opened by Mr. Walker. This old lady, after an illness of three months' severe suffering, recovered perfectly, left Wakefield for Harrogate, and is now (1882) in fair health, having had no return whatever of her former complaint. Her body is feeble, but her mind extraordinarily clear and bright for a lady who has passed her eighty-first year.

\section{ARTIFICIAL ERUPTION PRODUCED BY MECHANICAL MEANS.}

BY ALFRED SANGSTER, M.B., M.R.C.P.LOND., PHYSICIAN TO THE SKIN DEPARTMENT, CHARING-CROSS HOSPITAL. (From Notes by Mr. BAKER, late House-Physician.)

L. F_- a delicate, fair-haired girl, aged seventeen, presented herself at the out-patient department at Charing. cross Hospital with a peculiar and very disfiguring appearance of the face. Both cheeks were entirely covered by a thin, brownish, sharply defined, even incrustation, beyond which there was a broad hyperæmic border. On looking closely into the surface, many minute scattered hæmorrhagic points were seen. There was a large pigmented area on the neck, which the patient stated had been similarly affected. The appearances were not those of eczema or erythematous lupus, and indeed were so unusual that some questions were put to the stepmother, who accompanied the patient, as to whether she had any suspicion that the eruption was produced artificially. She, however, was quite surprised at the suggestion. All that could be elicited from the patient herself was that the face had "burnt" very much after exposure to cold wind, and that it presented the above-described appearance when she woke the following morning. She was admitted into the hospital.

From her history it appeared that she had good health until two years and a half ago, when she was laid up with an abscess in the ankle, the result of a sprain. Soon afterwards she had another abscess in the back, about the level of the second lumbar vertebra. The scars of these abscesses were quite conspicuous. Some deep scars on the left hand were accounted for by abscesses following a poisoned wound of the finger. There were some broad superficial scars on the extremities, which were 'said to have been left by patches such as those above described on the face. Some elongated excoriated patches were discovered corresponding to the position of the waistband.

During her stay in the hospital the patient frequently complained of sore-throat, which at these times seemed swollen externally about the thyroid cartilage. Several fresh patches made their appearance (during the night) while she was under observation, one on the left forearm, one at the bend of the left elbow, and a third over the sternal region. They were irregular in outline, those on the forearm and sternum three or tour inches in the longest measurement. All pre- sented the same initial heat and redness, with subsequent superficial incrustation and surrounding hyperæmia ; they ran a similar course, gradually fading, the crust falling in about ten days, leaving the part somewhat livid but nor scarred. Although the case was closely watched, and out suspicions concealed as much as possible, we were unable to prove how the patches were produced, at length it was decided to accuse the patient. Accordingly, Mr. Baker, the house-physician (to whom I am indebted for great interest taken in the case), having excoriated his arm by continued friction with the pulp of his fingers, taxed her with the deception. She confessed to having produced the patehes in the same way. She stated that she had not menstruated for two years, but that at the periods when the flow should have returned, red irritable patches used to appear on different parts of the body ; these she rubbed and excoriated, afterwards she found she could produce the patches at will, without any previous spontaneous reddening of the part. When she produced a patch on the site of an old one a superficial scar was left. The reason she gave for producing: the patches was that her life at home was unhappy, her father was a drunkard, she worked long hours, and had to give all her earnings to her stepmother, who was unkind to her.

Remarks.-Although the eruption was looked upon as artificial from the commencement there were one or two facts connected with it which gave it a certain reality, or, at least, called for explanation. It was astonishing that a young girl should so disfigure herself, even for a special purpose. However, it seems to be a fact that artificial eruptions are not unfrequently produced on the face presumably to enlist greater sympathy. The broad superficial scars, which she stated had been left by the eruption, suggested the employment of some chemical, such as those usually had recourse to. Yet the conditions under which the patient was placed whilst in the hospital rendered the concealment of any such substance almost impossible. The occurrence of patches in the region of the waistband hardly looked like design. The girl was rather cheerful and well-spoken; she was not hysterical, and, in the absence of assignable motive, would not have been suspected of fraud. The sequel proved, however, that she was overwrought, harshly dealt with, and probably in need of rest, which she could only obtain by feigning disease. There may have been truth in what was said about the amenorrhoea and the spontaneous red irritable patches; however, she did not mention this at first, and she menstruated while in the hospital. The case seems worthy of record as an example of the production of an artificial eruption by mechanical means, most artificial eruptions being due to the application of some chemical or irritant: nitric acid, cantharides, mustard, \&c.

\section{ACUTE PROLAPSUS OF RECTUM; SUGGES- TION AS TO TREATMENT.}

BY C. E. MACNAMARA, L.R.C.S.I, RESIDENT SURGEON TO THE PUBLIC HOSPITAL, GEORGE TOWN, BRITISH GUIANA.

Prolapsus RECTI of the above form is a hernia the reduction of which unquestionably is often, even to a skilful and patient surgeon, a matter of anxiety, and always to the conscious patient an operation of considerable pain. And I therefore think that any suggestion as to a mode of treating it in a manner which deprives it of these objections will be received gratefully by many surgeons. The following plan $I$ have found in many obstinate cases to have been speedily and uniformly successful. I may here, perhaps, be allowed to mention that when I was on leave and at home during 1879, I acquainted my father, Professor Rawdon Macnamara of Dublin, with the plan, and he, as Surgeon to the Meath Hospital, and also Surgeon to the Lock Hospital of that city, has had many opportunities of testing its value, and has reported favourably. With this excuse for touching upon a subject which has been written upon in articles by various authors, I will briefly state the mode of treatment. $A$ case in point may be acceptable.

A. $\mathrm{B}$ - was admitted into the Public Hospital under the 